\title{
Metalinguistic and Linguistic Knowledge in Foreign Language Learners
}

\author{
Sepideh Alipour \\ Jahrom University, Iran
}

\begin{abstract}
This study aimed at providing further insight into the relationship between metalinguistic and linguistic knowledge. Thirty-eight university students took two tests (metalinguistic and linguistic cloze test) in the study. Their tests were analyzed for accuracy. Bivariate correlation and paired sample t-test were conducted. The study has discovered a moderate positive relationship between $\mathrm{L} 2$ learners' metalinguistic knowledge and the ability to correct, describe, and explain L2, and their proficiency in L2 by the use of a written test.
\end{abstract}

Index Terms—metalinguistic awareness, linguistic knowledge, writing

\section{INTRODUCTION}

It is of the utmost priority, before presenting the analysis of the point at issue, to briefly discuss the several meanings with which the term "metalinguistic knowledge" has been used.

Metalinguistic awareness is defined as one's ability to consciously, think about language and its nature by means of the skills mentioned bellow: (Roehr, 2007):

1. an awareness that a language is not just the symbols of that language, but it can go beyond the meaning

2. an awareness that the words and their referents are quite separate (meaning is in the language user's mind, not in the words, i.e. Sue is Sue, and I will be the same person even if others call me something else)

3. an awareness that language is rule-based and its structure can be manipulated, you can write things in many different ways.

Metalinguistic knowledge is typically defined as the learners' ability to correct, describe, and explain second language (L2) errors (Roehr, 2007). The famous linguist, Noam Chomsky (1975), has defined the field of metalinguistic as "the subject knowledge of the characteristics and structures of language." Metalinguistic awareness refers to the understanding that language is a system of communication, connected to the rules, and forms the basis for the ability to discuss different ways of using language (Kuile, et al., 2010).

Roehr (2007) pointed out that metalinguistic ability refers primarily to "the possibility of using language above the surface structures, of using language in an abstract way, of thinking deeply it, while making use of it in our understanding and observations"

Metalinguistic is an awareness of the language, its structures and functions that let the speakers of that language to think about and use the language consciously. It consists of the knowledge and awareness of phonemes, syllables, rhyme, and morphology (Andrew, 2004).

A number of studies have examined the relationship between learners' implicit and explicit knowledge (Hulstijn \& Hulstijn, 1984). In all of these studies, explicit knowledge is defined as the learners' being able to explain language, its features such as structures and phonemes, while implicit knowledge was operationalized through using these features in oral or written forms of language.

Bialystok (1999) has defined metalinguistic awareness as the ability to attend to and reflect upon the properties of language. Metalinguistic awareness can be defined as the awareness of the features of the language that gives the speakers of that language the ability of not only comprehending or producing utterances, but also checking the linguistic form and structure underlying the meaning of the utterances (Malakoff, 1999).

Metalinguistic knowledge is also defined as learners' explicit knowledge about language (Bialystok, 1999), and linguistic knowledge is defined as the learners' implicit knowledge about language. There are two types of knowledge: explicit and implicit. While implicit knowledge is acquisition of knowledge about the underlying structure of a language by a process which takes place naturally and without conscious attention, explicit knowledge is conscious in the sense that individuals attend to particular aspects of the stimulus and structures (Ellis, 2008).

Metalinguistic knowledge is parallel to explicit knowledge about L2 categories and relations between categories (Roehr, 2007) and the important processes such as proficient manipulation of metalinguistic knowledge defined in this way are analysis of language and creative use of language (Ellis, 2005). Therefore, describing and explaining an error needs the tagging of a linguistic unit and also the connection of this unit with a stored pedagogical structure that explains (an aspect of) its use in phrases, sentences, or connected discourse (Roehr, 2007)

In her 1999 study, Bialystok proposed the idea that metalinguistic awareness involves the operation of control as a cognitive process. She defines control as the process of selective attention, the ability to monitor and regulate the 
processing of information. It concerns the intentional selection and application of knowledge employed in solving metalinguistic problems.

Grammatical competence is the knowledge in the mind that occurs automatically and is not available to introspection, implicit knowledge that a speaker has about language, and that comes from the distinct but the interrelated unit of the mind associated with the human language faculty (Chomsky, 1975).

L2 proficiency is defined in a limited way as learners' knowledge of L2 grammar and vocabulary, that is, a subcomponent of general language ability (Bachman and Palmer 1996).

The research on metalinguistic presents an asymmetry between linguistic production and linguistic comprehension with comprehension seeming to be easier than production. It is in fact a very well known fact that learners learn to understand structures far earlier than to produce them (Bates, Thal, Finlay, \& Clancy, 2002).

The importance of having grammatical awareness is emphasised by many scholars for various reasons. Denham and Lobeck (2002), for instance, state this importance in regard with teachers that many English education textbooks comment on the necessity of teachers being aware of certain essential grammatical structures in order to help students identify patterns of errors.

Metalinguistic awareness is often assessed using tasks of syntactical awareness (Bialystok, 1999). Generally speaking, a metalinguistic task is the one that requires the individuals to reflect on the linguistic features of the language and the linguistic nature of the messages (Malakoff, 1999).

\section{The Importance of Metalinguistic Awareness}

Metalinguistic ability in the L2 is often promoted by classroom attention to the formal system of the L2. Metalinguistic awareness allows creative and unique language use that is unseen without such awareness (Malakoff, 1999). Past studies have shown that it is better to improve the metalinguistic awareness of the bilingual children, as the learning of two languages requires the learners to focus on the features of the two languages.

Metalinguistic awareness or explicit, conscious knowledge of form/meaning relationships in a language, usually considered as the ability to express thoughts about language, is one of the best investigated differences between bilinguals and monolinguals (Malakoff, 1999). Previous studies have shown that metalinguistic awareness has a positive correlation with upgraded reading ability in young children (Castles \& Coltheart, 2004). Metalinguistic awareness has been found to be closely linked to reading comprehension (Zipke, 2007). It was found that bilinguals have a better ability compared to monolinguals to understand an unknown language, mostly because of their greater metalinguistic awareness.

Knowledge and use of metalanguage is likely to make the development of an L2 learner's metalinguistic awareness easier, that is, 'an improved self-awareness and sensitivity to the forms and functions of language' (Carter, 2003), which can lead to language development (Berry, 2005).

There is considerable evidence ( $\mathrm{Hu}, 2002)$ that metalinguistic performance plays an important role in learning how to read. Children with deficient or inefficient comprehension and production processes might have to rely on their metalinguistic abilities in order to learn certain aspects of language. Several recent studies have discovered that there is a positive correlation between metalinguistic awareness and L2 proficiency. In a study involving 372 first-year undergraduate students in Hong Kong, Berry (2009) found that the students were, to a great extent, different in their knowledge of 50 items of metalanguage and that this knowledge was considerably correlated with their top grades in English, indicating 'a correlation between knowledge of language and proficiency in English'. Renou (2001) also found consistently significant correlations between metalanguistic awareness and L2 proficiency in a sub-sample of learners being taught French as an L2 through the grammar approach. but such a relationship was missing for the sub-sample being taught the foreign language through a communicative approach.

Some results have indicated that phonological awareness, as part of metalinguistic awareness may play a role in the comprehension of L2 learners. The greater the level of the phonological knowledge, measured by the means of phonological awareness tasks, the greater the level of speech comprehension (White and Ranta, 2002).

The study was guided by two research questions and two hypotheses:

RQ1 What is the relationship between advanced university-level learners' L2 proficiency and their L2 metalinguistic knowledge?

RQ2 Is there a difference between students' performance on metalinguistic test and their performance on linguistic test?

R H1 There is no relationship between students' performance on metalinguistic test and their performance on linguistic test.

R H2 Students' performances on the two tests are to some extent similar.

One of the limitations of the study is that it did not control for the age variable. As Burke and James (2000) state" it is more difficult for older people to retrieve known structures". Maybe different results will be obtained by students at different ages.

Also the study did not control for the level of proficiency and aptitude variable, as White and Ranta (2002) say: 'it is found that performance on metalinguistic Tasks co-varies with levels of L2 proficiency and levels of L2 attitude.

Linguistic knowledge was obtained just from the written measures of second language proficiency, and it is the limitation of the study. Students' performance on oral tests will be different from their performance on written tests. 
The findings of the study are about a specific sub-population of L2 learners, that is, university-level language learners who receive form-focused instruction. Therefore, the current findings may not be extended beyond such learners, due to its limitation.

\section{Methodology}

L2 learners' L2 proficiency, operationalized as knowledge of L2 grammar in the present study was assessed by means of an open-ended cloze test with 22 gaps to be answered by them. The reason behind using cloze test was to provide learners with context in which language is used. This test included a range of L2 features based on English grammar which were part of university courses.

The construct of L2 metalinguistic knowledge was operationalized by means of a test aimed at measuring learners' ability to correct, describe, and explain selected L2 features. This section had 30 sentences each of which with one underlined error. Learners were asked to correct, describe, and explain the underlined errors.

The L2 features tested in the description/explanation section of the metalanguage test were constructed in a way to match, to the extent possible, the items on the language test. The reason behind this was to find the correlation of the two tests, and if there is any correlation, it will be obtained under optimal condition, parallel tests, in this research.

The L2 features included in the language cloze test and the description/explanation section of the metalanguage test are summarized in Appendix A and Appendix B.

The participants consisted mainly of 40 EFL learners at the university level. 20 were in their first year of study and the remaining was in the second year of their study. This sample is representative of specific EFL learners, rather than general EFL learners.

The metalinguistic test and the language cloze test were administrated with three weeks interval. First the metalinguistic test was administrated and then the language test. The students were tested under the supervision of a superior student. The time allocated for the completion of each test was 45 minutes. Due to learners missing in the linguistic test, just 38 completed the second test, so their metalinguistic test was also deleted from the whole test.

\section{RESUlts AND ANALYSis}

The first research question examined the relationship between metalinguistic knowledge operationalized in terms of ability to correct, describe, and explain L2 errors, and linguistic proficiency operationalized in terms of ability to perform fill-in the blank tests. The first test had a scale between 0 and 30, and the second test had a scale of 0 and 22 . But in the statistics they were weighted against scale 30. Bivariate correlation was used to address the relationship between the two constructs. The 2 missing subjects were excluded from all the analysis.

The second question explored the difference between performances on each test. The difference was examined by conducting paired sample t-test and then comparing means of both groups.

Bivariate correlation and paired sample t-test are shown respectively in Table 1, and Table 2.

In order to address RQ1 bivariate correlation was calculated. Table 3 shows that the correlation between the two tests is significant ( $\mathrm{sig}=.001)$, so null hypothesis is rejected and performance on the two tests is related. But considering its numerical value (.534), this relationship is moderate.

TABLE 1

\begin{tabular}{|l|l|l|l|}
\hline Correlations & & metalinguistic_test & linguistic_cloze_test02 \\
\hline \multirow{3}{*}{ metalinguistic_test } & Pearson Correlation & 1 & $.534^{* * *}$ \\
\cline { 2 - 4 } & Sig. (2-tailed) & & .001 \\
\cline { 2 - 4 } & $\mathrm{N}$ & 38 & 38 \\
\hline \multirow{3}{*}{ linguistic_cloze_test02 } & Pearson Correlation & $.534^{* *}$ & 1 \\
\cline { 2 - 4 } & Sig. (2-tailed) & .001 & 38 \\
\cline { 2 - 4 } & $\mathrm{N}$ & 38 & \\
\hline \multirow{2}{*}{$* *$ Correlation is significant at the 0.01 level (2-tailed). } &
\end{tabular}

Descriptive statistics for the metalinguistic test and linguistic cloze test demonstrate that linguistic cloze test proved harder for the students than the metalinguistic test. In addition, the linguistic cloze test shows a larger standard deviation than the metalinguistic test. Considering the significance of the paired sample t-test (sig=.557), the second hypothesis is not rejected and students' performances on the two tests are nearly similar.

\begin{tabular}{|c|c|c|c|c|c|c|c|c|c|}
\hline \multicolumn{10}{|c|}{ Paired Samples Test } \\
\hline & & \multicolumn{5}{|c|}{ Paired Differences } & \multirow[b]{3}{*}{$t$} & \multirow[b]{3}{*}{ df } & \\
\hline & & \multirow[b]{2}{*}{ Mean } & \multirow[b]{2}{*}{ SD } & \multirow{2}{*}{$\begin{array}{l}\text { Std. } \\
\text { Error } \\
\text { Mean }\end{array}$} & \multicolumn{2}{|c|}{$\begin{array}{l}95 \% \text { Confidence Interval } \\
\text { of the Difference }\end{array}$} & & & \\
\hline & & & & & Lower & Upper & & & \\
\hline $\begin{array}{l}\text { Pair } \\
1\end{array}$ & $\begin{array}{l}\text { metalinguistic_test - } \\
\text { linguistic_cloze_test } \\
02\end{array}$ & .38789 & 4.25331 & .68998 & -1.01013 & 1.78592 & .562 & 37 & $\begin{array}{l}577.577 \\
0.577\end{array}$ \\
\hline
\end{tabular}




\section{DISCUSSIONS AND CONCLUSIONS}

With respect to the first question, it was found that in university level learners, metalinguistic knowledge; the ability to correct and explain errors in language; and linguistic knowledge were correlated.

With respect to the second question, the results of the analysis of students' performance on two tests, the ability to correct, describe and explain highlighted errors exceeds, to a small extent, the ability to produce those grammatical points. The reason is that as people get older, in fact it gets more and more difficult to retrieve structures. On the other hand, there seems to be no decrease in the language understanding capacity whatsoever (Burke \& James, 2000).

Language production, is also cognitively burdening, as it is a burden on respondents' shoulders to "search within their own mental storage of conscious knowledge about language in order to find the proper metalinguistic features to describe a language item. Similarly some respondents either did not answer or provided incorrect answer for the production test.

A plausible explanation for the relationship between metalinguistic knowledge and second language production is the design of the study. The positive correlation obtained is attributable to the items matched across both tests. Thus, learners who have knowledge of a specific linguistic feature as measured by linguistic cloze test also seem to have explicit knowledge of that feature.

Naturally, correlation just presents covariance and cannot reveal the direction of any cause-effect relationship, so no firm conclusions about the contribution of metalinguistic knowledge to L2 proficiency or vice versa can legitimately be made on the basis of the obtained statistics.

\section{IMPLICATIONS}

The study urged for the following implication. Given that grammar benefits language learning, helping students to connect their knowledge of grammar to language production (in the forms of production tests, writing) makes learning grammatical structures easier.

Finally, L2 teachers can use metalanguage in a proper way to help L2 learners connect new knowledge of the language with already established materials, materials acquired previously.

\section{APPENDix A. Linguistic Cloze Test}

No sooner had we decided not to fix the TV, ............... we found our children behaved as they used to be. .............. Pair of TV shows and game shows were forgotten. After some months neither the older, the younger complained about watching TV. Our older son surprised us by behaving in a more appropriate way than................ in the house.

We decided that we had better............. (break) the TV. By the time they got out of TV, there............ (be) a decline in their spirit .It is not natural to feel like ......... (run) our interests in such a short time, but the children were able to develop other interests. Both registered in a sport club and became professional in a sport game. We feel. (impatient) for the day to come and to see. one, their team or their rivals will win the game .

Now, instead of watching $\mathrm{TV}$, we talk about the issues of the day or............... (go) to cinema rather than............... (listen) to other people talk about such matters, and there is abenefit that we can discuss the issues ................ (far). Since that time much free time (be) saved for us.

Most people think that TV is an essential part of their lives, because of their interesting programms, but it has isolated people from their family and society and ............ (bring) about a sense of loneliness. The idea ............... TV would bring families together is not justified yet. In the short run it is true, but not in the long run that they become accustomed to Tv.

I didn't even notice him. (realistic), it was my daughter, who pulled at my coat and said: "Daddy, that man's cold". "If he had been inside, he................. (get cold)." Although I was in doubt, I made up my mind to help him. I went and talked to him. He suffered from cold and had difficulty ................... (make) himself underestood. I took him to the house. The boy................ real name was Micheal said that his parents were.................. (economic) and science teachers, and they were killed in an accident and their corpse is not yet found, that he is hoping that one day their corpse (find).

\section{ApPEndix B. Metalingustic Test}

\section{Tick the incorrect answer}

- Only about a half a year do the swallows spend time in the surrounding area of the San Juan Capistrano no Mission.

- No sooner had the curtain fallen when the audience jumped up from their seats.

- Those pair of silver bookends that the museum had ordered from a European dealer doing business in Africa, became lost en route to this country.

- The oldest contestant in the hundred-year cash surprised us spectators by running faster than everyone in the area.

- Most people think that wolf is a ferocious beast because of their reputation based on stories and movies; actually it is afraid of people. 
- When John died, in 1921, he had written and published 20 nature books and gave America much greater awareness of the wonders and joys in nature.

- The committee is hoping that a concert can be arranged imminently in which the works of Bach will play.

- Psychologists tell us that it is perfectly natural to feel like to run away from our responsibilities once in a while.

- The two teams are palying the championship game next week to see whom, the red team or the blue team, will win the pennent.

- When asked why he was painting a sunset, the man replied that he was paint Sunset because he wanted.

- By the educators introduced reforms in education, there has been a serious decline in achievement in fundamental subjects.

- Feeling impatiently for someone to return and give him an answer, the student paced up and down the hall.

- Neither George Washington or Abraham had ever seen an airpalne fly during his life time.

- The idea which the world may be destroyed by nuclear weapons has raised Qs about justification of their development and use.

- The Dow Jones average indicates the daily average value of stock shares that are purchase and sold through stock exchanges.

- One group was satisfied with the explanation whereas the other group wanted to explore the subject farther.

- Since 1782, the bald eagle, which signifies power and courage, is the national emblem of the united states.

- Sheep are among the most important animals that has been domesticated because they provide food and clothing; moreover, they are used in making other products such as soap and glue.

- Not being able to speak the language of the country which we were visiting, we naturally had difficulty to make ourselves underestod.

- perhaps a little known fact about Twain, which real name was Clemens, was that at one time, hoping to make a fortune, he prospected for gold.

- Although primary a vegetarian, the chimpanzee, a four-foot tall member of the ape family, likes eating meat occasionally.

- The farmer realized that he'd better, if he didn't want to have a total loss, to harvest his crop earlier than usual.

- All the designer had all kinds of samples, but she couldn't make up her mind which one to select.

- According to newspaper advertisements, there appears to be a great need today for economic and science teachers.

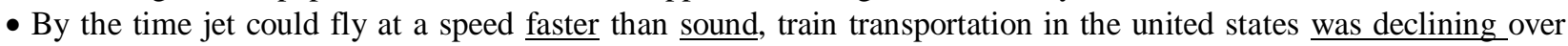
several decades.

- Mrs block is one of the women who, I believe, is running for office in this district.

- $\underline{\text { Realistic, }}$ there seems to be no way of setting the issue of water rights for fisherman to the satisfaction of all.

- Some examinations are exempt from paying income tax; foe example, a welfare organization need not to give money to the Department.

- If the drilling platform had built to withstand the violent storms, it wouldn't have collapsed.

- Don't you think that she would have helped you yesterday if he were able to?

\section{REFERENCES}

[1] Andrews, S. (1999). Why do L2 teachers need to 'know about language'? Teaching metalinguistics awareness and input for learning, Language and Education, 13(3), 161-177.

[2] Bachman, L., F and Palmer, A., S. (1996). Language Testing in Practice. Oxford University Press: Oxford

[3] Bates, E., Thal, D., Finlay, B., \& Clancy, B. (2002). Early language development and its neural correlates. Handbook of Neuropsychology, 6, 1-62

[4] Berry, R. (2009). EFL majors' knowledge of metalinguistic terminology: A comparative study. Language Awareness, 18, 113-128.

[5] Bialystok, E. (1999). Levels of bilingualism and levels of linguistic awareness. Developmental psychology, 24, 560-567

[6] Carter, R. (2003). Language awareness. ELT Journal, 57, 64-65.

[7] Castles, A., \& Coltheart, M. (2004). Is there a causal link from phonological awareness to success in learning to read? Cognition, 91, 77-111.

[8] Chomsky, N. (1975). Reflections on language. New York: Pantheon

[9] Burke, D., M, \& James, L., E. (2000). Phonological priming effects on word retrieval and tip-of-the-tongue experiences in young and older adults. Journal of Experimental Psychology, 26(6), 1378-1391.

[10] Denham, K., \& Lobeck, A. (2002). A practical grammar course: An annotated syllabus in syntax in the schools. The Journal of the Assembly for the Teaching of English Grammar, 18(2), 1-6.

[11] Ellis, R. (2005). Measuring implicit and explicit knowledge of a second language. SSLA Journal, 27, 141-172.

[12] Hu, G. W. (2002). Psychological constraints on the utility of metalinguistic knowledge in second language production. Studies in Second Language Acquisition, 24, 347-386.

[13] Kuile, T., H., \& Weldhuis, M. (2010). Bilingual education, metalinguistic awareness, and the understanding of an unknown language. Language and Cognition 14(2), 233-242.

[14] Malakoff, M. (1999). Translation skill and metalinguistic awareness in bilinguals. Journal of Language Processing, 144-166.

[15] Renou, J. (2001). An examination of the relationship between metalinguistic awareness and second-language proficiency of 
adult learners of French. Language Awareness, 10, 248-267.

[16] Roehr, K. (2007). Metalinguistic Knowledge and Language Ability in University-Level L2 Learners. Applied Linguistics, 29(2), 173-199.

[17] White, J., \& Ranta, L. (2002). Examining the interface between metalinguistic task performance and oral production in a second language. Language Awareness, 11, 259-290.

[18] Zipke, M. (2007). The role of metalinguistic awareness in the reading comprehension of sixth and seventh graders. Reading Psychology, 28, 375-396.

Sepideh Alipour, has an M.A in English teaching and now is teaching at English institutes and Jahrom University. Her fields of interest are applied linguistics, computer assisted language learning, and ESP. 